\title{
B $_{12}$ VITAMIN EKSIKLLIĞİ BULUNAN HASTALARDA ETIYYLOJIK FAKTÖRLER İLE LABORATUVAR VERILERİ ARASINDAKI ILISSKINIIN GERIYYE DÖNÜK DEĞERLENDİRILMESİ
}

\author{
RETROSPECTIVE ANALYSIS OF THE CORRELATION OF ETIOLOGICAL \\ FACTORS WITH LABORATORY FEATURES IN VITAMIN $B_{12}$ \\ DEFFICIENT PATIENTS
}

\author{
Bahar EMEN \\ Yasemin KILIÇ ÖZTÜRK \\ Mehmet Ali EREN \\ Emrah ÖZDEMİR \\ Faruk ÖZTÜRK \\ Erhan DÜZENLI \\ Deniz SARIASLAN
}

\section{ÖZET}

Amaç: Vitamin $\mathrm{B}_{12}$ eksikliği tanısı almış bireylerde eksikliğin şiddeti ile etiyolojik faktörler ve laboratuvar özellikleri arasındaki ilişkinin değerlendirilmesidir.

Gereç ve Yöntem: 2012 yılında Şanlıurfa Eğitim ve Araştırma Hastanesi Birinci Dahiliye Polikliniğinde $\mathrm{B}_{12}$ vitamin eksikliği tanısı almış hastalar geriye dönük incelendi. Bu hastaların klinik ve laboratuvar bulguları geriye dönük değerlendirildi.

Bulgular: Çalışmaya alınan 367 olgunun yaş ortalaması 38,71 $17,682 / y 11$ (14-90) olup 265'i kadın (\%72); 112'si(\%28) erkekti. Ortalama $\mathrm{B}_{12}$ vitamin düzeyleri 146,99 $\pm 32,642(44,75-196,80)$ olarak saptandı. Olguların yarısında (s=182) ağır $\mathrm{B}_{12}$ eksikliği vardı $(\leq 150 \mathrm{pg} / \mathrm{dl})$. Olguların vitamin $\mathrm{B}_{12}$ eksikliği seviyeleri ile yaş, cinsiyet, ilaç kullanımı (proton pompa inhibitörleri, metformin) ve tam kan sayımı ölçütleri arasında istatistiksel anlamlı ilişki bulunmadı.

Sonuç: Vitamin $\mathrm{B}_{12}$ eksikliği Şanlıurfa bölgesinde önemli bir sağlık sorunudur. Semptomatik hastalarda periferik kan sayımı incelemesi $\mathrm{B}_{12}$ eksikliği tanısını dışlamada yetersizdir.

Anahtar Sözcükler: Anemi, Makrositoz, Metformin, Proton Pompa İnhibitörü, Tam Kan Sayımı

\footnotetext{
İc Hastalıkları Kliniği,(Uz. Dr. B. Emen) Endokrinoloji Servisi, (Uz. Dr. MA. Eren)Kardiyoloji Servisi, (Uz. Dr. E. Özdemir) Acil Servis, (Uz. Dr. F. Öztürk, Uz. Dr. E. Düzenli)Anestezi Servisi, (Uz. Dr. D. Sarıaslan)

Mehmet Akif İnan Eğitim ve Araștırma Hastanesi, Sanlıurfa (Uz. Dr. Y.Kılıç Öztürk)

Aile Hekimliği Kliniği, İzmir Tepecik Eğitim ve Araştırma Hastanesi, İzmir

Yazıșma: Yasemin Kılıç Öztürk
} 


\section{SUMMARY}

Aim: To investigate the correlation of etiological factors with laboratory parameters in vitamin B12 deficient patients.

Material and Method: Patients who were recorded as B12 defficiency at the first Internal Medicine outpatient clinic in Sanlıurfa Training and Research Hospital during 2012 were included. Their clinical findings and laboratory findings were assessed,retrospectively.

Findings: The mean age of 367 patients were 38,71 $\pm 17,682 /$ years and $\% 72(n=265)$ of them were female. Mean vitamin B12 levels were $146,99 \pm 32,642 \mathrm{pg} / \mathrm{ml}$. Half of the patients had a severe B12 defficiency $(\leq 150 \mathrm{pg} / \mathrm{ml})$. No statistical significance was found between the B12 levels; age,gender, drugs(proton pump inhibitors, metphormin) and peripheral blood parameters.

Conclusions: Vitamin B defficiencyis a serious health problem at Sanliurfa region. The examination of peripheral blood parameters of symptomaic patients is not enough to exclude vitamin B12 defficiency.

Key words: Anemia, Complete Blood Count, Macrositosis, Metphormine, Proton Pump Inhibitor,

\section{GíRiș}

Kobalamin olarak da bilinen vitamin $\mathrm{B}_{12}$ ilk kez 1940’lı yılların sonlarında tanımlanarak pernisiyöz anemi tedavisinde kullanılmaya başlanmıştır. Vitamin $\mathrm{B}_{12}$ insan vücudunda yapılamadığından diyetle dışarıdan alınmalıdır. Vücudun günlük en az vitamin $B_{12}$ gereksinimi 2,5 $\mu \mathrm{g}$ 'dır. Bu ihtiyaç özellikle hayvansal kaynaklı gıdalarla sağlanabilir (1). Sağlıklı beslenen bir insan vücudunda $2 \mathrm{mg}$ karaciğerde, ve $2 \mathrm{mg}$ da vücudun diğer bölgelerinde olmak üzere toplamda $4 \mathrm{mg}$ vitamin B12 depolanır. Kobalamin eksikliği geliştiğinde ise gereken vitamin $\mathrm{B}_{12}$ 3-6 y1l süreyle bu depolardan karşılanabilir. Böbrek, karaciğer ve kalp vitamin $B_{12}$ yönünden çok zengin olup diğer kaslar, deniz ürünleri, yumurta, peynir ve süt ise daha az olmakla birlikte vitamin $B_{12}$ içerir (2). Sebzelerde ise çok az bulunduğundan özellikle vejetaryen diyetle beslenenlerde yetersiz alıma bağlı $\mathrm{B}_{12}$ eksikliğine sıkça rastlanır. Ayrıca gastrik disfonksiyon varlığı, intrensek faktör eksikliği, mide asidini azaltan ajanların kullanımı (proton pompa inhibitörleri-PPI, $\mathrm{H}_{2}$ reseptör antagonistleri) ve ileal absorbsiyonu etkileyen durumlar (metformin, kolestiramin,kolşisin gibi ilaçların kullanımı; paraziter hastalıklar) emilim bozukluğuna yol açarak vitamin $B_{12}$ eksikliğine neden olabilir $(3,4)$. Diyet ve sosyoekonomik nedenlerden büyük oranda etkilenen vitamin $\mathrm{B}_{12}$ eksikliği farklı toplumlarda \%3 ila \%40 arasında görülür $(5,6)$.

Vitamin $B_{12}$ eksikliği makrositer anemi ve bazı nöropsikiyatrik hastalıklarla ilişkilidir. Ayrıca son yıllarda hiperhomosisteinemi ve aterosklerozun başlamasında rol aldığı da tanımlanmıştır. Birçok organ sistemini etkileyebilen bu durumun tanısı serum vitamin $\mathrm{B}_{12}$ seviyelerinin ölçümüne dayanır (7). Ancak $\mathrm{B}_{12}$ ek- sikliğine eşlik eden pek çok hematolojik değişiklikler de söz konusu olabilir. Bunlardan bazıları megaloblastik anemi, makrositoz $(\mathrm{OEH}>100)$, artmış bilirubin ve LDH seviyeleri, düşük ya da normal retikülosit sayısı, düşük beyaz küre ve trombosit sayıları, makroovalositler ve hipersegmente nötrofillerdir. Ancak bu değişikliklerin şiddeti ile eksikliğin ciddiyeti arasında kesin bir ilişki tanımlanmamıştır $(2,7)$.

$\mathrm{Bu}$ çalışmada vitamin $\mathrm{B}_{12}$ eksikliği saptanan bireylerin serum $\mathrm{B}_{12}$ düzeyleri ile eksikliğe yol açabilecek durumlar ve laboratuvar değişikleri arasındaki ilişkiyi araştırmayı amaçladık.

\section{GEREÇ VE YÖNTEM}

Araştırmaya 01 Ocak 2012 ile 01 Ocak 2013 tarihleri arasında Şanlıurfa Eğitim ve Araştırma Hastanesindeki birinci Dahiliye Polikliniği'ne başvuran ve $\mathrm{B}_{12}$ vitamin eksikliği tanısı alan hastalar alındı .Laboratuvar bulguları ve hasta bilgileri hastane bilgi sistemi üzerinden geriye dönük olarak incelendi. Elde edilen veriler araştırmacılar tarafından düzenlenen standart forma kaydedildi. $B_{12}$ vitamini için 150-200 pg/mL arası hafif eksiklik, $100-150 \mathrm{pg} / \mathrm{mL}$ arası ağır eksiklik 100 $\mathrm{pg} / \mathrm{mL}$ 'niın altı ise çok ağır eksiklik olarak değerlendirildi.

Verilerin analizinde SPSS 17.0 istatistik programı kullanıldı. Rakamsal veriler aritmetik ortalama \pm standart sapma ve dağılım aralığı olarak; kategorik veriler sayı ve yüzde olarak ifade edildi. Parametrik özellik gösteren veriler Student t test, kategorik veriler için ki-kare ve sayısal değerlerin analizinde ise tekyönlü ANOVA testi kullanıldı. Rakamsal veriler arasındaki bağlantı Pearson korelasyon testi ile analiz edildi. Sonuçlar \%95 güven aralığında değerlendirildi. 


\section{BULGULAR}

Çalışmaya alınan 367 olgunun yaş ortalaması $38,71 \pm 17$, 682/yıl olup 265'i $\operatorname{kad} ı(\% 72)$; 112'si $(\% 28)$ erkekti. Ortalama $\mathrm{B}_{12}$ vitamin düzeyleri $146,99 \pm 32,642$ olarak saptand1. Olguların 34'ünde çok ağır ( $B_{12}$ seviyesi $100 \mathrm{pg} / \mathrm{mL}$ ve altında);151'inde ağır (101-150 pg/mL) 182'sinde hafif (151-200 pg/mL) düzeyde $\mathrm{B}_{12}$ eksikliği vardı. Tam kan sayımı incelemelerinde ortalama eritrosit sayıs1 4,83 $\pm 0,571$; hematokrit düzeyi 41,42 $\pm 5,268$; ortalama eritrosit hacmi(OEH) $85,67 \pm 10,116$; ortalama trombosit hacmi (OTH) 8,10 $\pm 1,698$ idi.

Olguların 162'si (\%44,2) proton pompa inhibitörü, 52 'si (\%14) metformin kullanıyordu. Gaitada parazit görülme sıklığı ise \%5,1 ( $\mathrm{s}=19)$ düzeyinde idi (Tablo 1).

$\mathrm{B}_{12}$ düzeyi çok düşük olan hasta grubunun yaş ortalaması diğer gruplardan düşük olmakla birlikte grupların yaş ortalamaları arasındaki fark istatistiksel olarak anlamlı bulunmadı $(\mathrm{p}=0.178)$. Tüm gruplarda ortalama hemoglobin değerleri ve eritrosit sayıları sağlıklı erişkinler için anemi sınırında seyrederken gruplar arasında anlamlı fark yoktu $(\mathrm{p}=0,432 ; 0,183)$. Çok ağır $\mathrm{B}_{12}$ eksikliği olan grubun TSH düzeyi ortalamaları değerlendirildiğinde gruplar arasında istatistiksel olarak anlamlı fark bulunmadı $(\mathrm{p}=0,103)$. Ortalama eritrosit ve trombosit hacimleri ile $\mathrm{B}_{12}$ eksikliğinin şiddeti arasındaki ilişki anlamsızdı ( $\mathrm{p}=0.052 ; 0248)$ (Tablo 2).

Tablo 1. $B_{12}$ eksikliği düzeyine göre $B_{12}$ eksikliğine yol açabilecek faktörlerin analizi

\begin{tabular}{|c|c|c|c|c|c|c|c|c|}
\hline & & \multicolumn{2}{|c|}{$100 \leq \mathrm{B}_{12}$} & \multicolumn{2}{|c|}{$101 \leq \mathrm{B}_{12} \leq 150$} & \multicolumn{2}{|c|}{$151 \leq \mathrm{B}_{12} \leq 200$} & \multirow[b]{2}{*}{$\mathrm{p}$} \\
\hline & & $\mathrm{s}$ & $\%$ & $\mathrm{~s}$ & $\%$ & $\mathrm{~s}$ & $\%$ & \\
\hline \multirow[t]{2}{*}{ Cinsiyet } & Kadın & 21 & 62 & 98 & 65 & 136 & 75 & 0.09 \\
\hline & Erkek & 13 & 38 & 53 & 35 & 46 & 25 & \\
\hline \multirow[t]{2}{*}{ PPI kullanımı } & Yok & 18 & 53 & 86 & 57 & 101 & 55 & 0.91 \\
\hline & Var & 16 & 47 & 65 & 43 & 81 & 45 & \\
\hline \multirow[t]{2}{*}{ Metformin } & kullanmiyor & 26 & 76 & 135 & 89 & 154 & 85 & 0.12 \\
\hline & kullanıyor & 8 & 24 & 16 & 11 & 28 & 15 & \\
\hline \multirow[t]{2}{*}{ Gaitada parazit } & Yok & 30 & 88 & 145 & 96 & 173 & 95 & 0.18 \\
\hline & Var & 4 & 12 & 6 & 4 & 9 & 5 & \\
\hline Toplam & & 34 & & 151 & & 182 & & 367 \\
\hline
\end{tabular}

S: sayı PPİ:Proton pompa inhibitörü

Tablo 2. $B_{12}$ eksikliği düzeyine göre demografik özellikler ve laboratuvar değerlerinin analizi

\begin{tabular}{|c|c|c|c|c|}
\hline & $\begin{array}{c}\text { Çok ağır } \mathrm{B}_{12} \text { eksikliği } \\
\text { Ortalama }\end{array}$ & $\begin{array}{c}\text { Ağır } \mathrm{B}_{12} \text { eksikliği } \\
\text { ortalama }\end{array}$ & $\begin{array}{c}\mathrm{B}_{12} \text { eksikliği } \\
\text { ortalama }\end{array}$ & $\mathrm{P}$ \\
\hline kadın/erkek & $21 / 13$ & $98 / 53$ & $136 / 46$ & \\
\hline yaş(yıl) & $43 \pm 2.87$ & $39 \pm 1.45$ & $37.6 \pm 1.30$ & 0.178 \\
\hline B12 & $86.1 \pm 2.24$ & $127.7 \pm 1.21$ & $174.3 \pm 1.0$ & 0.00 \\
\hline KKH & $4752100 \pm 108000$ & $4808400 \pm 49070$ & $4869000 \pm 39420$ & 0.432 \\
\hline Hb & $12.8 \pm 0,37$ & $13.3 \pm 0.16$ & $12.9 \pm 0.14$ & 0.183 \\
\hline Htc & $40.4 \pm 1.01$ & $41.9 \pm 0.45$ & $41.2 \pm 0.36$ & 0.215 \\
\hline OEH & $85.27 \pm 1.83$ & $87.03 \pm 0.80$ & $84.61 \pm 0.75$ & 0.052 \\
\hline ОТН & $8.30 \pm 0.30$ & $7.93 \pm 0.13$ & $8.21 \pm 0.13$ & 0.248 \\
\hline TSH & $2.13 \pm 0.22$ & $1.91 \pm 0.13$ & $2.07 \pm 0.08$ & 0.103 \\
\hline
\end{tabular}

KKH:Kırmızı kan hücresi;; OEH: Ortalama eritrosit hacmi; OTH:Ortalama trombosit hacmi;

Yapılan Pearson Korelasyon analizinde serum $\mathrm{B}_{12}$ vitamini düzeyleri ile tam kan sayımı ölçütleri arasında ilişki saptanmadı $(\mathrm{p}>0,05)$.

\section{TARTIŞMA}

Vitamin $\mathrm{B}_{12}$ eksikliği farklı ülkelerde \%3'ten \%40'a kadar değişen sıklıklarda görülmekle birlikte dünya 
genelinde bir toplum sağlığı sorunu olarak kabul edilmektedir $(5,6)$. Sorunun ciddiyetini netleştirmeye yönelik geniş ölçekli epidemiyolojik araştırma sayısı ise oldukça azdır. Bölgede daha önce anne ve bebekler üzerinde yapılan bir araştırmada gebelerde $\% 72$, bebek kordon kanında ise \%41 gibi yüksek oranlarda B12 eksikliği tanımlanmıştır (8). Çalışma Dahiliye Polikliniğine başvuran ve tetkiklerinde $B_{12}$ eksikliği belirlenen hastalar üzerinde yapıldığından tarama niteliği taşımamaktadır. Ancak $\mathrm{B}_{12}$ düşüklüğü saptanan olguların yaklaşık \%9'unun ( $\mathrm{s}=34$ ) çok ağır eksiklik; $\% 41$ 'inin ( $\mathrm{s}=151$ ); yarısının ise hafif eksiklik ile karşı karşıya olduğu görülmektedir. Bazı araştırmalarda 350 $\mathrm{pg} / \mathrm{ml}$ seviyesindeki $\mathrm{B}_{12}$ düzeylerinde bile eksiklik bulgularının saptanabileceği belirtilmektedir $(9,10) . \mathrm{Bu}$ değerin sınır alınması durumunda çalışmada değerlendirilen tüm hastalar çok ağır $B_{12}$ eksikliği olarak kabul edilebilir $(9,10)$. İzmir'de $\mathrm{B}_{12}$ eksikliği düşünülen çocukların incelendiği ve $160 \mathrm{pg} / \mathrm{ml}$ 'nin altındaki değerlerin ağır eksiklik olarak kabul edildiği bir araştırmada 8 çocuktan birinde ağır eksiklik tanımlanmıştır (11). $\mathrm{Bu}$ çalışmada ise $150 \mathrm{pg} / \mathrm{ml}$ sınırına rağmen oranın \%50 seviyesinde olması hem Dahiliye Polikliniğine başvuran hastalarda kronik hastalık sıklığı; hem de bölgenin sosyoekonomik düzeyi ile ilişkili olabilir. Ancak yine de bölgede $B_{12}$ eksikliğinin ciddi bir sağlık sorunu boyutunda olabileceğini de düşündürmektedir.

50 yaş üzeri bireylerde yapılan bir araştırmada daha önceki bazı çalışmalara benzer şekilde erkeklerde $B_{12}$ eksikliğinin daha sık görüldüğü bildirilmiştir $(13,14)$. Ancak literatürde birçok araştırmada ise vitamin eksikliği ile cinsiyet arasında ilişkiye rastlanmamıştır $(11,12) . . \mathrm{Bu}$ çalışmada $\mathrm{B}_{12}$ görülme sıklığı incelenmemekle birlikte cinsiyet ile $B_{12}$ düzeyleri arasındaki ilişki anlamsız bulunmuştur. Çalışmada kadın hasta sayısının fazla olması bölgede çalışan kadın nüfusun azlığ1 ve mesai saatlerinde hastanelere erkeklerden daha sık başvurabilmeleri ile ilişkilendirilmiştir. $B_{12}$ eksikliği olan tüm olgularda proton pompa inhibitörü kullanım oranı \%44,2 bulunmuştur. Bu kullanım sıkl1ğ1 literatürde tanımlanan peptik ülser ve helikobakter pylori eradikasyonu tedavisi alma sıklığından yüksek oranda olup PPI kullanımın ile $\mathrm{B}_{12}$ eksikliği arasındaki ilişki ile uyumludur (3). Metformin kullanımı ile $\mathrm{B}_{12}$ eksikliği görülme sıklığındaki artış birçok araştırmada belirtilmekle birlikte literatürde $\mathrm{B}_{12}$ düzeyine etkisi ile ilgili yeterli çalışma bulunmamaktadır. $\mathrm{Bu}$ çalışmada ise $B_{12}$ eksikliğinin şiddeti ile metformin kullanımı arasında ilişki bulunmadı.
Yapılan çalışmalarda diabetes mellitus, akut koroner sendrom, inme, preeklempsi, renal arter stenozu ve hiperkolesterolemi gibi hastalıklarda Ortalama trombosit hacmi(OTH) artışı olduğu gösterilmiştir (15). $B_{12}$ eksikliği de nöropsikiyatrik belirtiler ve ateroskleroza yol açmaktadır $\mathrm{Bu}$ açıdan OTH ile $\mathrm{B}_{12}$ seviyeleri arasındaki ilişki araştırılmış, anlamlı ilişki bulunmamıştır.

$\mathrm{B}_{12}$ eksikliğine bağlı anemide genellikle trombositopeni, lökopeni ve Ortalama eritrosit hacmi(OEH) değerinin normalden yüksek olduğu bilinmektedir. Ancak sadece hemoglobin ve OEH değerinin incelenmesi, megaloblastik anemi tanısında her zaman yol gösterici olmayabilir ve tanı için yalnız başına kullanılmaması önerilmektedir $(2,7,14)$. Çünkü Türkiye'de demir eksikliği de oldukça sık görülmektedir. Demir eksikliği makrositozu maskeleyebileceği gibi demir eksikliği ile birlikte $\mathrm{B}_{12}$ vitamin eksikliği varlığı da OEH'nin normal ya da düşük saptanmasına ve yanılgıya yol açabilmektedir. $B_{12}$ vitamini eksikliği ile ilgili yapılan çalışmalarda $\mathrm{B}_{12}$ eksikliğinin hemogram değerlerine yansımayabileceği bildirilmektedir $(11,16,17)$. Çalışmamızda benzer şekilde vitamin $\mathrm{B}_{12}$ eksikliğinin şiddeti ile laboratuvar verilerinin belirleyici olmadığı görülmüştür. $\mathrm{B}_{12}$ eksikliğinin şiddeti açısından fikir vermede tam kan sayımı yetersiz kalmaktadır. Olgularda demir eksikliği ile ilgili kayıtların değerlendirilmemiş olması ise araştırmanın kısıtlılıklarındandır.

\section{SONUÇ}

Şanlıurfa bölgesinde vitamin $\mathrm{B}_{12}$ eksikliği önemli bir sağlık sorunudur. Periferik tam kan sayımı bulgularının her zaman $B_{12}$ eksikliği için güvenilir olmayabileceği akılda tutulmalıdır. Bu açıdan eksiklik belirti ve bulguları olan bireylerde tam kan sayımı tabloyu desteklemese de serum vitamin $B_{12}$ ölçümü önerilmelidir.

\section{KAYNAKLAR}

1. O'Leary F, Samman S. Vitamin $B_{12}$ in Health and Disease. Nutrients 2010; 2(3): 299-316.

2. Maralcan M, Ellidokuz E. Vitamin $B_{12}$ Eksikliği. Güncel Gastroenteroloji 2004;8(3):199-204.

3. Thomson ABR, Sauve MD, Kassam N, Kamitakahara H. Safety of the long-term use of proton pump inhibitors. World J Gastroenterol. 2010 May 21; 16(19): 2323-30.

4. Pierce SA, Chung AH, Black KK. Evaluation of vitamin $B_{12}$ monitoring in a veteran population on long-term, high-dose metformin therapy. Ann Pharmacother. 2012;46(11):1470-6. 
5. Garci'a-Casal MN, Osorio C, Landaeta M, Leets I, Matus P, Fazzino F , Marcos E. High prevalence of folic acid and vitamin B12 deficiencies in infants, children, adolescents and pregnant women in Venezuela. European Journal of Clinical Nutrition 2005;59:1064-70.

6. Koç A, Koçyiğit A, Ulukanlıgil M, Demir N. Şanlıurfa yöresinde 9-12 yaş grubu çocuklarda $B_{12}$ vitamini ve folik asit eksikliği sıklığı ilebağırsak solucanlarıyla ilişkisi, Çocuk Sağlı̆̆ ve Hastalıkları Dergisi 2005;48:308-15.

7. Ocakçı $\mathrm{S}$. Birinci basamakta demir ve $\mathrm{B}_{12}$ eksikliği anemilerine yaklaşım. Smyrna Tıp Derg 2012;eksay11:51-3.

8. Koc A, Kocyigit A, Soran M, Demir N, Sevinc E, Erel O. High frequency of maternal vitamin B12 deficiency as an important cause of infantile vitamin B12 deficiency in Sanliurfa province of Turkey. Eur J Nutr 2006;45:291-7.

9. Lindenbaum J, Healton EB, Savage DG, Brust JCM, Garrett TJ, Podell ER, et al. Neuropsychiatric disorders caused by cobalamin deficiency in the absence of anemia or macrocytosis. N Engl J Med 1998;318:1720-8.

10. Carmel R. Current concepts in cobalamin deficiency. Annu Rev Med 2000;51:357-75.

11. Çolak AA, Anıl M, Toprak B, Köse E,Üstüner F. Cocuklarda $\mathrm{B}_{12}$ vitamin düzeyi ve periferik tam kan sayımı değerleri ile iliş̧kisi. İzmir Dr. Behçet Uz Çocuk Hast. Dergisi 2012; 2(2):75-9.
12. Öncel K, Özbek MN, Onur H,Söker M, Ceylan M. Diyarbakır İlindeki Çocuklarda ve Adölesanlarda $\mathrm{B}_{12}$ Vitamin ve Folik Asit Düzeyleri. Dicle Tıp Dergisi 2006;33:163-9.

13. Özdem $S$, Gültekin $M$. Yaşlılarda serum $B_{12}$ vitamini, folik asit ve plazma homosistein düzeyleri. Turk $J$ Geriatr. 2006;9(2):59-64.

14. Hamdi Kara İH, Kandiş H, Bahçebaşı T, Köylü OK, Sayın S,ve ark.. Check-up polikliniğine Başvuran 50 yaş üzeri bireylerin Folat, $B_{12}$ Vitamini Düzeyleri ve Anemi Yönünden Değerlendirilmesi. Turk J Biochem 2010;35(4);350-5.

15. Bath P, Algert C, Chapman N, Neal B;for the PROGRESS Collaborative Group. Association of Mean Platelet Volume With Risk of Stroke Among 3134 Individuals With History of Cerebrovascular Disease. Stroke 2004;35:622-6.

16. Erden S,Şakar Ş,Koç Z, Şen F, Çakır H,Gelincik A,et al. The Properties of Vitamin B12 Deficiency in the Patients of an Outpatient Clinic. Turkiye Klinikleri J Med Sci 2010;30(6):1845-51.

17. Oosterhuis WP, Niessen RWLM, Bossuyt PMM, Sanders GTB, Sturk A. Diagnostic value of the mean corpuscular volume in the detection of vitamin $\mathrm{B}_{12}$ deficiency. Scand J Clin Lab Invest 2000;60:9-18.

\section{ILETişim}

Yasemin KILIÇ ÖZTÜRK

İzmir Tepecik Eğitim ve Araştırma Hastanesi

Aile Hekimliği Kliniği- Yenişehir/IZMiR

Tel:232-4696969

e-posta:dryko38@gmail.com 